\title{
Seismic behavior analysis of wind turbine tower affected by hydrodynamic pressure based on a simplified calculation model
}

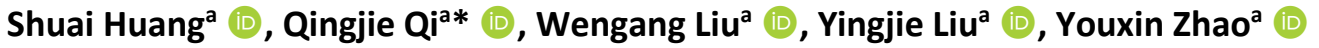 \\ a China Coal Research Institute, Beijing 100013, China. E-mails: huangshuai3395@163.com, qiqingjie@126.com, zgjxlgdx@163.com, \\ 44013482@qq.com, 987426338@qq.com \\ * Corresponding author
}

https://doi.org/10.1590/1679-78256196

\begin{abstract}
The interaction between water and structure will inevitably lead to the hydrodynamic pressure, which could change the dynamic behavior of the wind turbine tower under earthquake action. Based on the Morison hydrodynamic theory, a simplified calculation method of hydrodynamic pressure was proposed, and the effects of different water depths and hydrodynamic pressure on the seismic behavior of the wind turbine tower is investigated. The main results include: wind turbine tower in deep water is sensitive to water, and the deformation and energy dissipation capacity of the wind turbine tower are decreased affected by the hydrodynamic pressure; the influence of hydrodynamic pressure on the acceleration and displacement is related to the high frequency components of the seismic wave, and the effect of hydrodynamic pressure on the internal force, displacement, and acceleration increases with the increasing of the water depths under different earthquakes. Finally, a shaking table test is carried out, and the experimental results are in good agreement with the calculated results using our proposed method.
\end{abstract}

\section{Keywords}

hydrodynamic pressure; wind turbine tower; earthquake action; shaking table test; water depth

\section{Graphical Abstract}
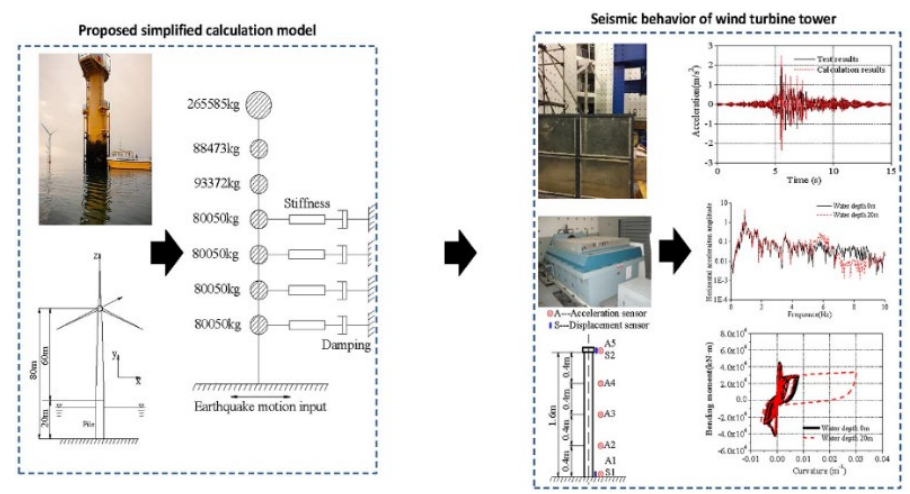

Received: July 21, 2020. In Revised Form: July 27, 2020. Accepted: July 27, 2020. Available online: August 03, 2020 https://doi.org/10.1590/1679-78256196

(c) Latin American Journal of Solids and Structures. ISSN 1679-7825. Copyright @ 2020. This is an Open Access article distributed under the terms of the Creative Commons Attribution License, which permits unrestricted use, distribution, and reproduction in any medium, provided the original work is properly cited. 


\section{Introduction}

Because offshore wind energy resources are rich, all coastal states will take ocean development as a national strategy. The global wind power industry is rapidly expanding from land to sea. Wind turbine tower vibrates and deforms under strong earthquake, which causes the surrounding water to shake; then the sea water reacts on the wind turbine tower in the form of hydrodynamic pressure, affecting and changing the dynamic response of the wind turbine tower. The research of hydrodynamic pressure is less generally in the world. There is a lack of systematic and effective method to calculate the hydraulic. The existing domestic structure seismic design specification of the hydrodynamic pressure is no longer suitable to the design requirements of deep-water wind turbine tower.

The hydrodynamic pressure generated by the interaction of water and wind turbine tower is not negligible for the seismic design of wind turbine tower under strong earthquake action. There are few researches on the seismic response of deep-water wind turbine tower considering hydrodynamic pressure, and there is no systematic and effective calculation method at home and abroad. At present, when considering the hydrodynamic pressure problem on the structure during the earthquake, researchers usually put forward the corresponding approximate analytical solution based on the linear radiation wave theory. The hydrodynamic pressure under earthquake was first proposed by Westergaard (1998) on the dam in 1933, and put forward the calculation formula of hydrodynamic pressure on the vertical dam surface under horizontal seismic movement based on the assumption that the structure moves rigidly in incompressible fluid. The study about the effect of hydrodynamic pressure on the structure in water is first conducted by Savage (Hoshikuma 2000), and the analytical solution of the equivalent additional mass of water on a cylindrical structure is obtained by the shaking table test. Chopra and Goyal (1991) proposed an effective method for calculating the additional mass of moving water of the tower structure under the horizontal earthquake action considering the interaction between water and structure; however, the amplitude and distribution of the additional mass depend on the modal shape of the elastic structure. Terro and Rohman (2007) analyzed the difference between the linearization and the nonlinear Morison equation in the analysis of Marine structures and proposed a modified linearized Morison equation. Feng et al. (2006) established the calculation equation of the hydrodynamic pressure of the pier under earthquake by using the Trefftz function and microwave theory, and found that the influence of hydrodynamic pressure on structure mainly depends on the ratio of additional mass to structure deadweight. Zhao et al (2019) proposed an analytical solution to the hydrodynamic pressure of a rigid cylinder under the horizontal earthquake action. Zhang et al. (2012), Ye (2013) Sun and Pan (2013), Cao (2013), and Walker and Taylor (2005) used Morison equation and Radiation wave theory to analyze the influence of hydrodynamic pressure on the offshore structure under earthquake, and found that influence of hydrodynamic pressure on the dynamic response of the structure cannot be neglected. Therefore, the influence of hydrodynamic pressure on the seismic response of the wind power tower is a key problem in seismic design. Chen et al. (2008), Gao and Zhu (2006), and Lai et al. (2004) assumed that the maximum hydrodynamic pressure is the interaction result between water and structure, and studied the seismic response of deep water bridge piers considering the interaction between water and pier using Morison equation. Martinelli et al. (2011), Pilato et al. (2008), Zhou (2015), Xiang and Liu (2015), Lin et al. (2016), and Xiang (2008) established the finite element model of the tunnel and bridge pier in the sea, and determined the influence laws of hydrodynamic pressure on the seismic dynamic response of the tunnel and pier. Although the influence of hydrodynamic pressure on the structure has been studied at home and abroad, the analytical solution in previous studies are usually applicable to the calculation of hydrodynamic pressure on a more regular structure, and is not suitable for the seismic design of deep-water wind turbine tower with variable cross-section.

In our study, a simplified calculation method of hydrodynamic pressure was proposed which adapted to time-history response analysis on wind turbine tower based on the Morison hydrodynamic theory, and the effect of hydrodynamic pressure on seismic behavior of the wind turbine tower is investigated. Finally, the shaking table test is carried out to verify the accuracy of the calculation results in our study.

\section{Simplified calculation method of hydrodynamic pressure}

According to Morison's hydrodynamic theory (Morison et al. 1950), the influence of structure on water movement was ignored, and it is assumed that the action of water on the structure is caused by undisturbed acceleration and velocity fields; therefore, the hydrodynamic pressure on structure is composed of two parts: the inertial force and the resistance, and the calculation formula is shown in Equation (1).

$F(x, z, t)=F_{I}+F_{D}=\left(C_{M}-1\right) \rho \Delta V(\dot{u}-\ddot{x})+\frac{1}{2} C_{D} \rho A_{p}(u-\dot{x})|u-\dot{x}|$ 
where $\rho$ is the density of water; $\Delta \mathrm{V}$ is the volume of the underwater structure; $\mathrm{Ap}$ is the cross-sectional area, $\mathrm{u}$ and $\dot{u}$ are the absolute velocity and the absolute acceleration of water; $\ddot{x}$ and $\dot{x}$ are relative acceleration and relative velocity of the structure; CM is the hydrodynamic inertia force coefficient; CD is the Hydrodynamic drag coefficient.

Because the influence of cylinder structure on water is ignored, the cylinder structure motion will not produce the movement of water, and the velocity and acceleration of water particle are both zero. The total hydrodynamic pressure on the cylinder structure per unit length in the $X$ axis direction is shown in Equation (2).

$F_{w}=-\left(C_{M}-1\right) \rho \Delta V \ddot{x}-\frac{1}{2} C_{D} \rho A_{p} \dot{x}|\dot{x}|$

Because the resistance term at the right end of the above equation is nonlinear, it is difficult to calculate in detail, and the quasi-linearization is adopted to calculated, as shown in Equation (3).

$\dot{x}|\dot{x}|=x_{r m s} \sqrt{\frac{8}{\pi}} \dot{x}$

where $x_{r m s}$ is the mean square of the velocity.

Then, the hydrodynamic pressure on the cylinder structure could be calculated as shown in Equation (4).

$F_{w}=-\left(C_{M}-1\right) \rho \Delta V \dot{x}-\frac{1}{2} C_{D} \rho A_{p} \sqrt{8 / \pi} x_{r m s} \dot{x}$

Therefore, the dynamic equation of the wind turbine tower under earthquake action is expressed as Equation (5).

$M \ddot{x}+C \dot{x}+K x=-M \ddot{x}_{g}-\left(C_{M}-1\right) \rho V\left(\ddot{x}+\ddot{x}_{g}\right)-\frac{1}{2} C_{D} \rho A_{p} x_{r m s} \sqrt{8 / \pi}\left(\dot{x}+\dot{u}_{g}\right)$

According to the research of Lai (Lai et al. 2004) and Goto. H. (Goto and Toki, 1965), the additional resistance of the water acting on the cylinder structure is very small compared with the additional inertial force under earthquake action, and the additional resistance can be ignored. Therefore, our study proposes that the hydrodynamic resistance term can be ignored, and only the additional mass term can be considered when calculating the hydrodynamic pressure on the cylindrical structure under earthquake action. Therefore, the dynamic equation of the wind turbine tower under earthquake action can be expressed as shown in Equation (6).

$M \ddot{x}+C \dot{x}+K x=-M \ddot{x}_{g}-\left(C_{M}-1\right) \rho V\left(\ddot{x}+\ddot{x}_{g}\right)$

It is assumed that the relative velocity of water and structure is constant between two adjacent elements, and the force acting on the $i$ th node of the structure is half of the total force acting on the element connected to point $i$; therefore, the equivalent additional mass of the water at node $\mathrm{i}$ is shown in Equation (7).

$M_{i w}=\sum\left(C_{M}-1\right) \rho V l_{i j}$

where $\mathrm{j}$ is the node adjacent to node $\mathrm{i} ; l_{i j}$ is half the effective length of the element $\mathrm{ij}$.

Therefore, the dynamic equation of the wind turbine tower under earthquake action can be simplified as shown in Equation (8).

$M \ddot{x}+C \dot{x}+K x=-M \ddot{x}_{g}-M_{w}\left(\ddot{x}+\ddot{x}_{g}\right)$

Therefore, the calculation of the hydrodynamic pressure will be greatly simplified. The hydrodynamic additional inertial force can be directly converted into the form of additional mass and applied to solving the dynamic motion equation of the wind turbine tower in deep water. 
Therefore, the calculation method of the influence of the hydrodynamic pressure on the dynamic response of the wind turbine tower under earthquake action is greatly simplified, and the additional inertial force term is directly converted into additional mass to apply to the dynamic motion equation of the wind turbine tower. And the simplified calculation model is shown in Fig.1.
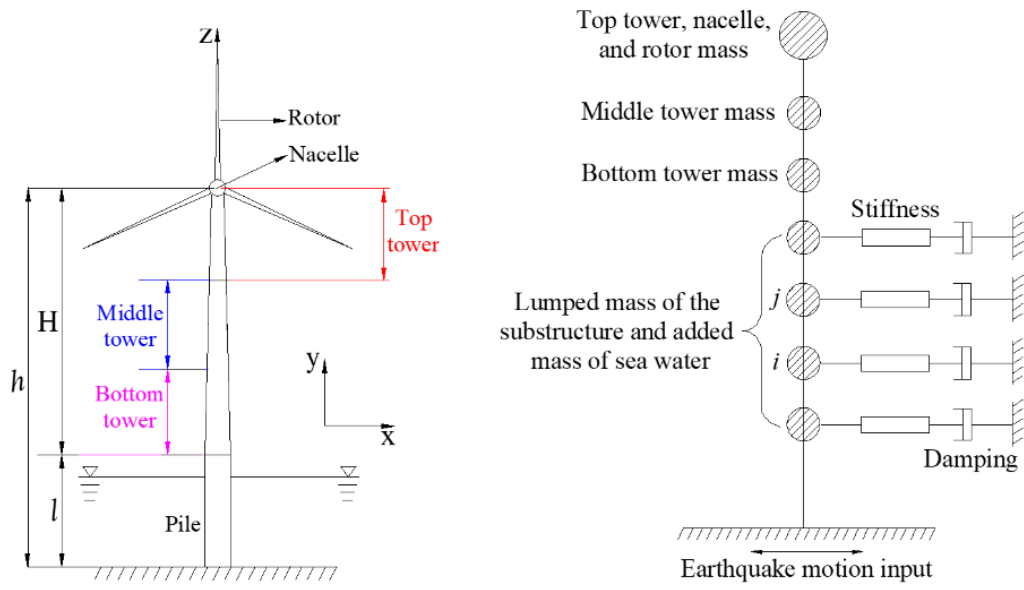

Fig.1 The simplified calculation model

\section{Engineering application examples}

\subsection{Calculation model}

This study takes a single-pier wind turbine tower located in the Yellow Sea as the research object. The wind turbine tower is location in the active seismic zone. The maximum water depth is $20 \mathrm{~m}$, and the tower height is $60 \mathrm{~m}$, and the pile above the ground is $20 \mathrm{~m}$. The single-pier wind turbine tower is located in the class II site, and the seismic fortification intensity is 8 degrees. The tower body adopts a variable-section and variable-wall-thickness cylindrical structure; the material of the tower and the pier above the ground is Q345C steel. The yield strength of the material is $\sigma y=345 \mathrm{MPa}$, modulus of elasticity is $E=2.06 \times 1011 \mathrm{~Pa}$, and Poisson ratio is $\gamma=0.3$. The tower outer diameter was $3.07 \mathrm{~m} \sim 4.5 \mathrm{~m}$, and the wall thickness was $18 \mathrm{~mm} \sim 50 \mathrm{~mm}$. The coefficient of hydrodynamic additional inertial force $\mathrm{CM}=2.0$, and the water density is $1000 \mathrm{~kg} / \mathrm{m} 3$. When there is water, the additional mass of dynamic water obtained from the simple calculation method of hydraulic pressure is added to the corresponding position of the underwater structure of the wind turbine tower. The masses of the wind turbine tower are determined, as shown in Fig. 2.
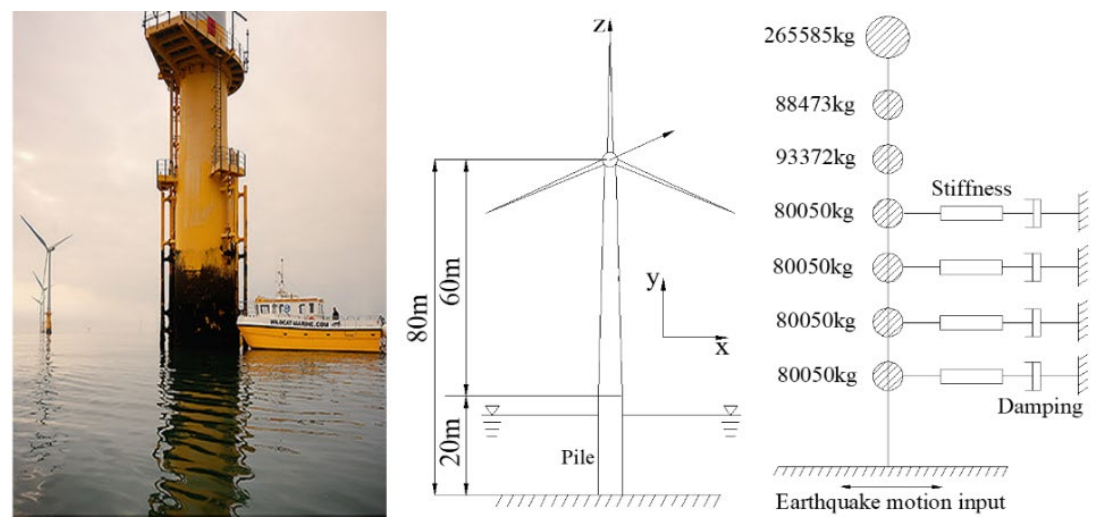

Fig.2 Single-pile wind turbine tower diagram

The yield strength of the material $\sigma y=345 \mathrm{MPa}$, modulus of elasticity $E=2.06 \times 1011 \mathrm{~Pa}$, and poisson ratio $\gamma=0.3$. The stress-strain relations of steels adopt the bilinear model recommended in Japanese Standard Specification for Highway Bridges (Japan Road Association 2002), as shown in Fig.3. This curve simplifies the plastic stage and enhanced stage of the material into a diagonal line. The corresponding elasticity modulus was E/100. The bending capacity parameters of the tower bottom section are shown in Table 1. 
Table 1 Bending capacity parameters

\begin{tabular}{cccccc}
\hline $\begin{array}{c}\text { Physical } \\
\text { quantity }\end{array}$ & $\begin{array}{c}\text { Yielding moment } \\
\boldsymbol{M}_{\boldsymbol{y}}(\mathrm{MN} \cdot \mathrm{m})\end{array}$ & $\begin{array}{c}\text { Yield curvature } \\
\boldsymbol{\phi}_{\boldsymbol{y}}\left(\boldsymbol{m}^{-\mathbf{1}}\right)\end{array}$ & $\begin{array}{c}\text { Limit bending moment } \\
\boldsymbol{M}_{\boldsymbol{u}}(\mathbf{M N} \cdot \mathbf{m})\end{array}$ & $\begin{array}{c}\text { Ultimate curvature } \\
\boldsymbol{\phi}_{\boldsymbol{u}}(\mathbf{m}-\mathbf{1})\end{array}$ & $\begin{array}{c}\text { Curvature ductility } \\
\text { factor } \boldsymbol{\phi}_{\boldsymbol{u}} / \boldsymbol{\phi}_{\boldsymbol{y}}\end{array}$ \\
\hline Values & 30.6 & 0.0007 & 40.56 & 0.0146 & 15.87 \\
\hline
\end{tabular}

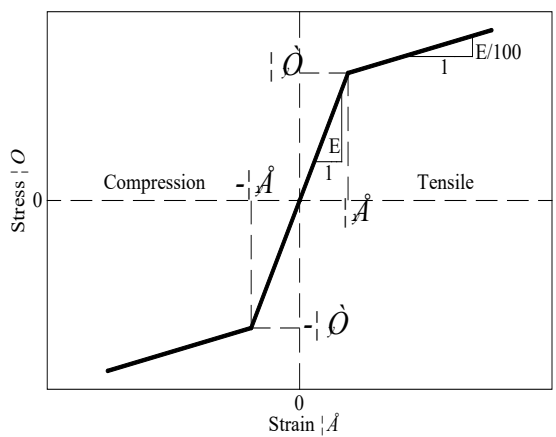

Fig.3 Constitutive model of the wind turbine tower

The wind load is applied to the particle by concentrated force, and the standard value of wind load is calculated according to the code (GB50135-2019, 2019), as shown in Equation (9).

$\omega_{k i}=\beta_{z i} \mu_{s} \mu_{z B i} \omega_{0}$

where $\omega_{k i}$ is the standard value of the wind load acting on the unit projected area at the $z$ height of the wind turbine tower; $\omega_{0}$ is the basic wind pressure, and the basic wind pressure of 50 years return period is $0.7 \mathrm{kN} / \mathrm{m} 2$, according to the code (GB50009-2012, 2012); $\mu_{z B i}$ is the height variation factor of wind pressure at the $z$ height of the wind turbine tower; $\mu_{s}$ is the shape coefficient of the wind load; $\beta_{z i}$ is the wind fluttering factor at the $\mathrm{z}$ height of the wind turbine tower.

For the dynamic balance equation of the single-pile wind turbine tower under the earthquake action, there are more mature numerical solutions at present, including central difference method, Wilson- $\theta$ method, and Newmark- $\beta$ method. Newmark- $\beta$ method is an unconditional and stable implicit integral scheme. The equation could obtain the stable solution when the parameter values are $\beta=0.125 \sim 0.25$ and $\gamma=0.5$, and the time step size $\Delta t$ does not affect the stability of the solution. According to the solving steps of the Newmark- $\beta$, the dynamic response of the single-pile wind turbine tower under earthquake action could be obtained when the time history of the earthquake load is known.

\subsection{Free vibration characteristic analysis}

The free vibration characteristic analysis is the important parameter for the seismic dynamic analysis of the wind turbine tower; therefore, before the seismic response analysis, the natural vibration characteristics of the wind turbine tower were firstly analyzed with and without the influence of water. We compared the order- 1 and order- 2 mode periods obtained from our proposed simplified calculation model and finite element method respectively, as shown in Table 2. Because our proposed simplified calculation model could not output the mode of the actual model, we used finite element method to simulate the mode of the actual model. Fig.4 shows the first two mode shapes of the wind turbine tower.

Table 2 Periods comparison between the simplified calculation model and Finite element method

\begin{tabular}{ccccccc}
\hline & \multicolumn{2}{c}{ Water depth 0m } & & \multicolumn{2}{c}{ Water depth 0.4m } \\
\cline { 2 - 3 } \cline { 5 - 7 } Method & $\begin{array}{c}\text { Order-1 mode } \\
\text { period (s) }\end{array}$ & Order-2 mode & & Order-1 mode & Order-2 mode \\
& 1.16 & period (s) & & period (s) & period (s) \\
\hline Simplified calculation model & 1.25 & 0.71 & 1.45 & 0.89 \\
Finite element method & 0.75 & 1.54 & 0.98 \\
\hline
\end{tabular}




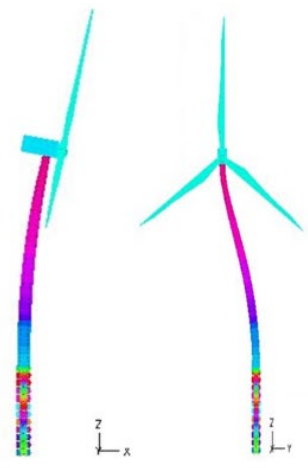

(a) Water depth $0 \mathrm{~m}$

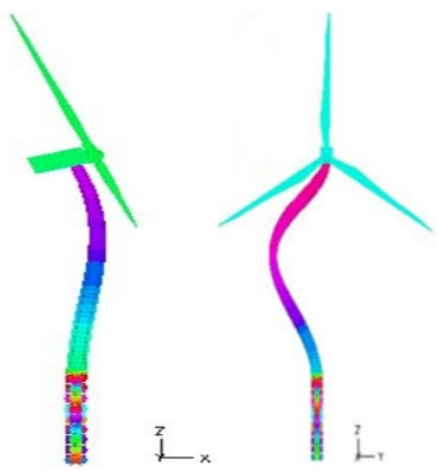

(b) Water depth $20 \mathrm{~m}$

Fig.4 The first two mode shapes of the wind turbine tower

As shown in Table 2 and Fig.4, the order-1 and order-2 mode periods obtained from our proposed simplified calculation model and finite element method respectively are close, and the maximum error is within $10 \%$.Taking the period obtained from our proposed simplified calculation model as example, the order-1 and order- 2 mode periods are $1.16 \mathrm{~s}$ and $0.71 \mathrm{~s}$ respectively without influence of the water, which show that the wind turbine tower belongs to long period structure. The order- 1 and order- 2 mode periods increase $24.9 \%$ and $25.2 \%$ with the influence of the water depth $20 \mathrm{~m}$. The vibration modes are bending deformation without the influence of the water, and the vibration modes are combined bending deformation and torsion deformation with the influence of the water. Consequently, the influence of water on the natural vibration characteristics of the wind turbine tower cannot be ignored.

\section{Effect of hydrodynamic pressure on dynamic response of wind turbine tower}

\subsection{Selection of seismic waves}

According to the Code for Seismic Design of Buildings (GB50011-2010, 2010), the key engineering structure in accordance with the seismic fortification intensity 8 degrees need to raise at least one earthquake fortification. In our study, the seismic fortification intensity is 9 degrees, and the horizontal design peak acceleration is 400Gal. In order to consider the randomness of the earthquake, the seismic waves are less than three; however, the code is not clear on the selecting of the seismic wave types. According to the Japanese code (Japan Road Association 2002), near-field and farfield seismic waves whose sites types are II are selected, and the far-field seismic waves are referred to as T1, and the near-field seismic waves are referred to as T2. The acceleration time histories of the seismic waves are shown in Fig.5, and the basic characteristics of the seismic records are shown in Table 3. Because the code pointed out that the influence of hydrodynamic pressure on the dynamic response of structures under vertical earthquake action is negligible, and the seismic waves are loaded in a single horizontal direction.

Table 3 Basic characteristics of the seismic records

\begin{tabular}{|c|c|c|c|c|c|}
\hline Type & Earthquake name & Magnitude & $\begin{array}{l}\text { Epicentral Distance } \\
\qquad(\mathbf{k m})\end{array}$ & Record location & $\begin{array}{c}\text { Epicentral } \\
\text { distance (km) }\end{array}$ \\
\hline T1-II-1 & Hotan earthquake in 1968 & 7.5 & 100 & $\begin{array}{l}\text { Plate island bridge } \\
\text { foundation }\end{array}$ & 362.62 \\
\hline T1-II-3 & $\begin{array}{c}\text { Hokkaido Dongchong } \\
\text { earthquake in1994 }\end{array}$ & 8.1 & 178 & ONNETO bridge & 364.84 \\
\hline T2-II-1 & Kobe earthquake in1995 & 7.2 & 11 & TAKATORI station & 686.83 \\
\hline T2-II-3 & & & 1 & Osaka gas station & 736.33 \\
\hline
\end{tabular}




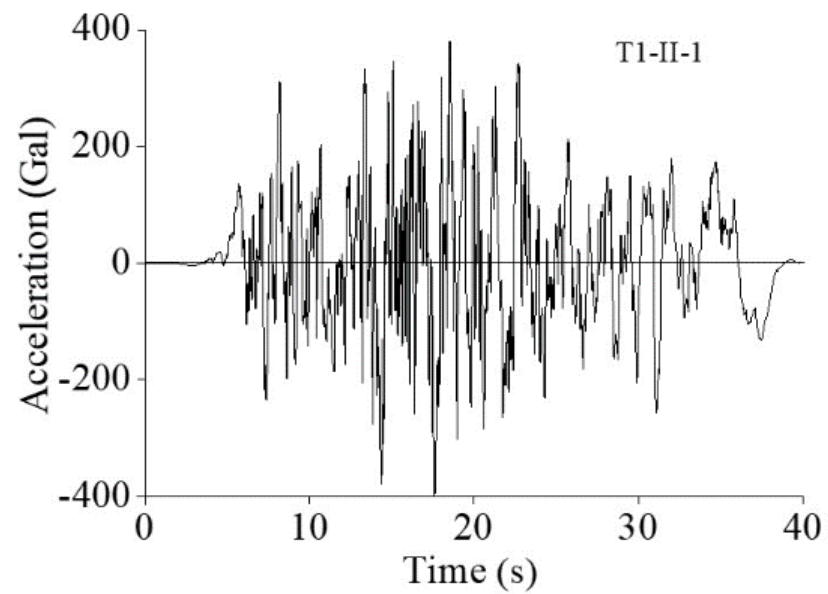

(a) T1-II-1

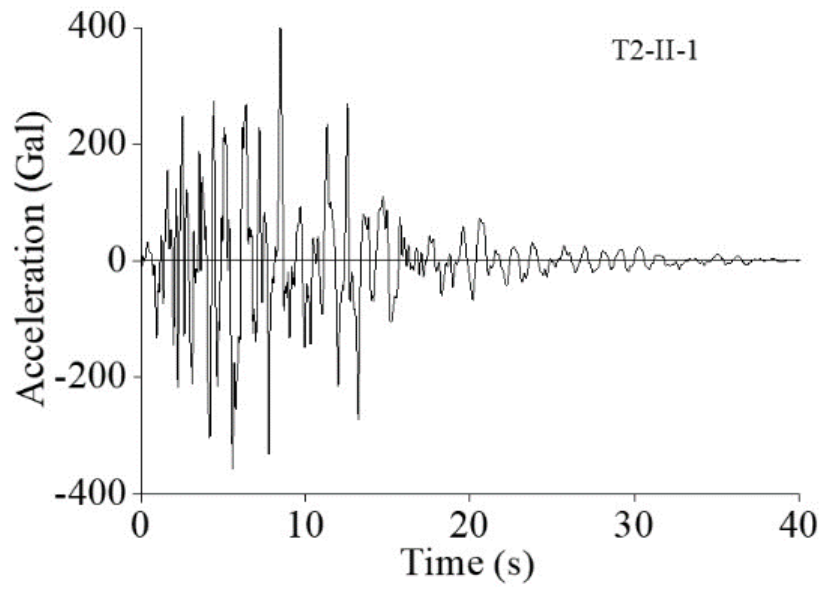

(c) T2-II-1

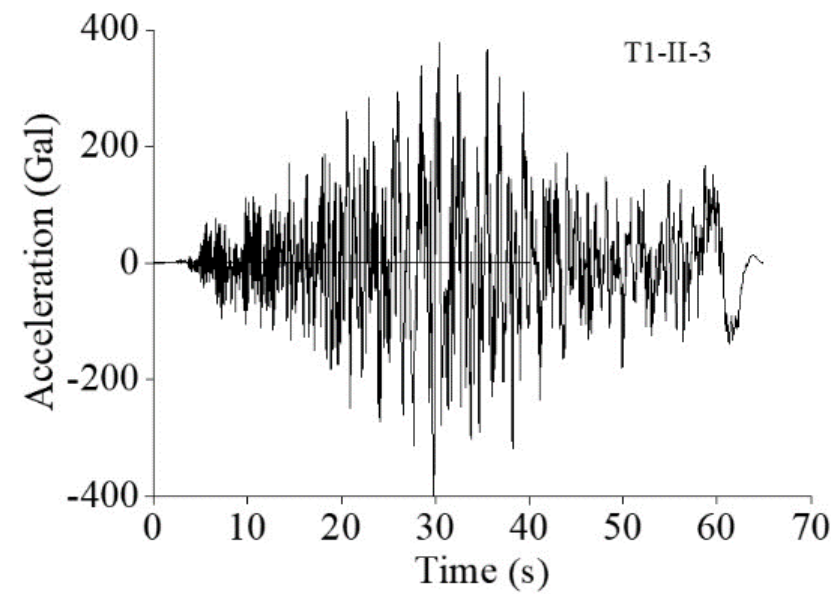

(b) T1-II-3

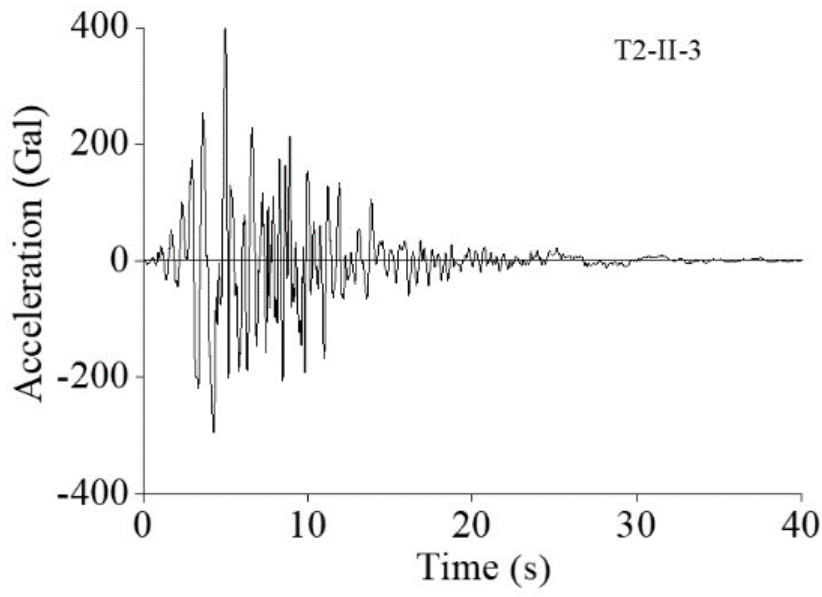

(d) T2-II-3

Fig.5 Acceleration time histories of the seismic waves

\subsection{Internal force analysis}

In order to study the influence of hydrodynamic pressure on the internal force of wind turbine tower under the earthquake action, the influence coefficient $R$ is used to represent the influence degree of hydrodynamic pressure on the seismic response of the wind turbine tower. The definition of the $R$ is shown in Equation (10).

Failure rate $=\frac{F}{F+S}$

where R1 is the dynamic response of wind turbine tower with the hydrodynamic pressure influence; R2 is the dynamic response of wind turbine tower without the hydrodynamic pressure influence.

By using the our proposed simplified calculation method of hydrodynamic pressure, the hydrodynamic pressure is directly converted into the form of additional mass and applied to solving the dynamic motion equation of the wind turbine tower in deep water. The shear force and bending moment are calculated using our proposed the simplified calculation model. The influence coefficient of hydrodynamic pressure on the internal force along the wind turbine tower height was investigated when the water depth is $20 \mathrm{~m}$, as shown in Fig.6. 


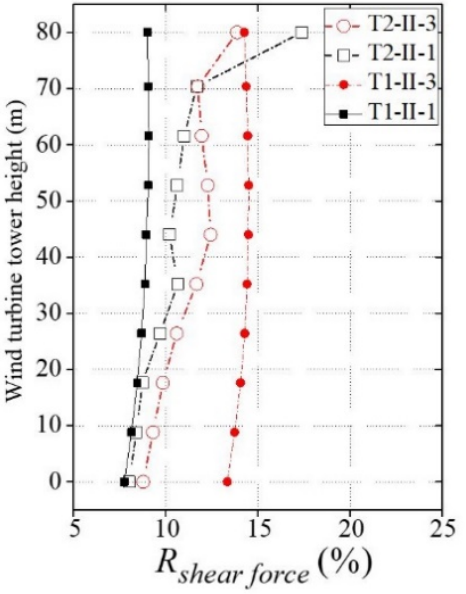

(a) Shear force

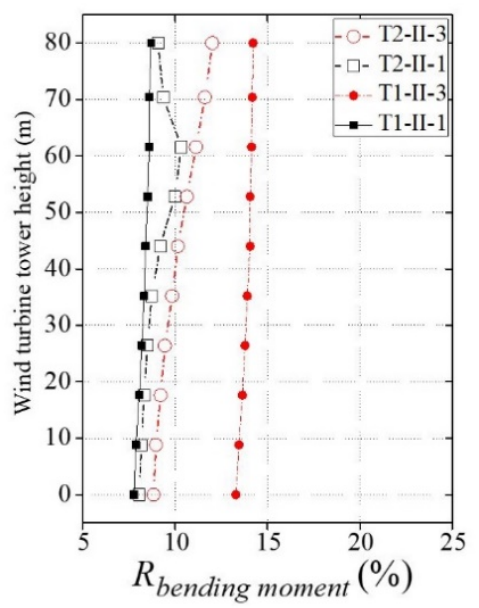

(b) Bending moment

Fig.6 Effect of hydrodynamic pressure on internal force of wind turbine tower

We can see in Fig.6, the effect of hydrodynamic pressure on the internal force of wind turbine tower is significant. For example, for the shear force at the wind turbine tower bottom, the hydrodynamic pressure makes the maximum shear force increase by $18.03 \%$ under earthquake (T2-II-1) action, and $8.99 \%$ under earthquake (T1-II-1) action. For the bending moment at the wind turbine tower bottom, hydrodynamic pressure makes the maximum bending moment increase by $14.22 \%$ under earthquake (T1-II-3) action, and 7.96\% under earthquake (T2-II-1) action.

The movement characteristic of the high-rise structure top is the key parameter of its aseismic behavior; therefore, we calculated the horizontal displacement and acceleration of the wind turbine tower top with and without influence of the hydrodynamic pressure under near-field earthquake (T2-II-1) and far-field earthquake(T1-II-1), as shown in Fig.7 and Fig.8.
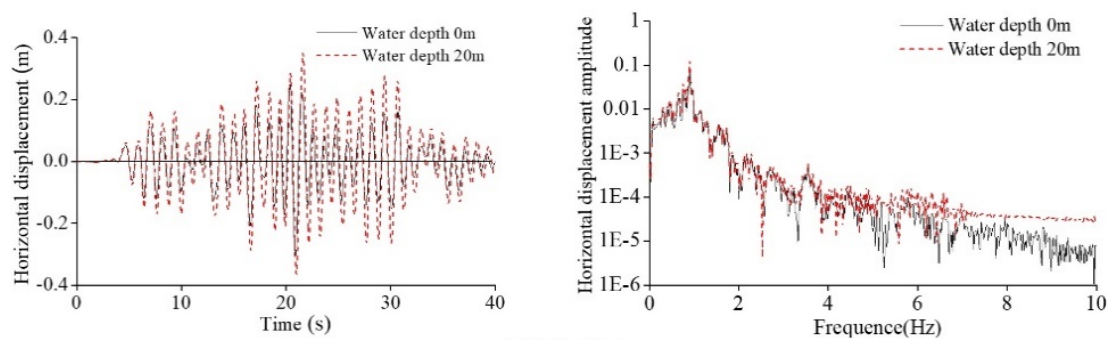

(a) T1-II-1
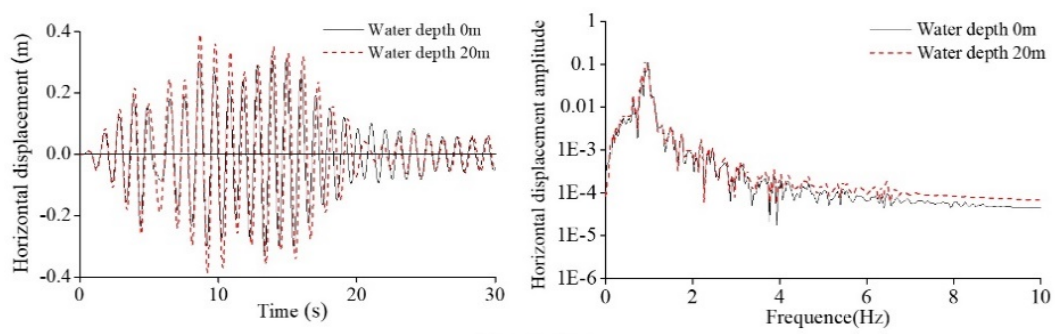

(b) T2-II-1

Fig.7 Horizontal displacement of the wind turbine tower top

As shown in Fig.7, because the hydrodynamic pressure changes the natural vibration characteristics of the wind turbine tower, the horizontal displacement of wind turbine tower top is greater in water depth $20 \mathrm{~m}$ than that without influence of water. It can be seen from the Fourier spectrum, below the $5 \mathrm{~Hz}$, the horizontal displacement amplitude with the influence of hydrodynamic pressure is consistent with that without the influence of hydrodynamic pressure. Above the $5 \mathrm{~Hz}$, due to the influence of hydrodynamic pressure, the amplitude attenuation of the horizontal displacement is obviously less than that without the influence of hydrodynamic pressure, which means the hydrodynamic pressure increases the horizontal displacement response mainly due to the high-frequency components of the ground motion. 

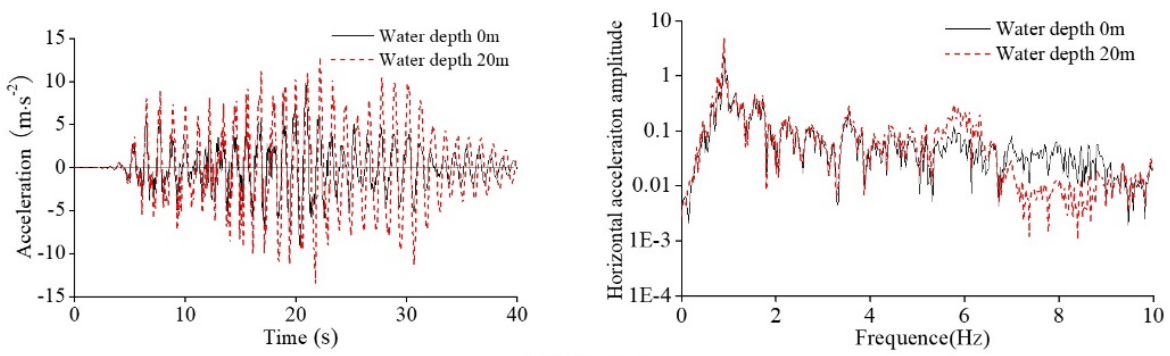

(a) T1-II-1
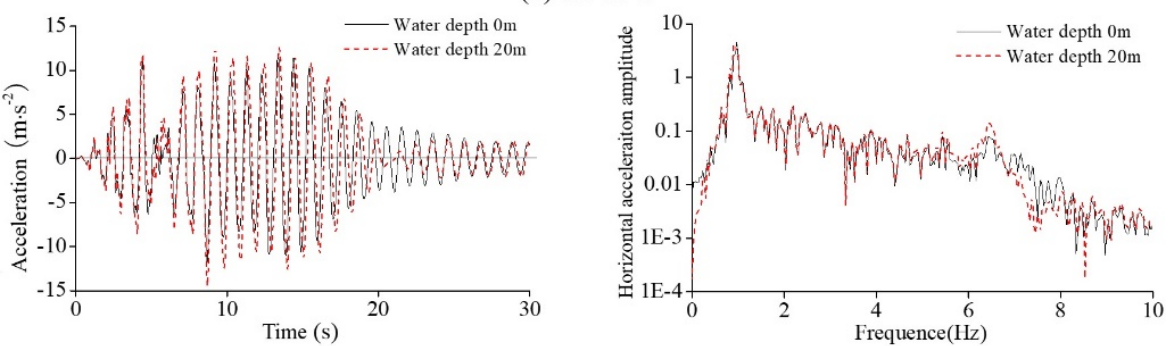

(b) T2-II-1

Fig.8 Acceleration of the wind turbine top

As shown in Fig.8, the horizontal acceleration of wind turbine tower top is greater in water depth $20 \mathrm{~m}$ than that without influence of water. And it can be seen from the Fourier spectrum, below the $5 \mathrm{~Hz}$, the horizontal acceleration amplitude with the influence of hydrodynamic pressure is consistent with that without the influence of hydrodynamic pressure. Above the $5 \mathrm{~Hz}$, due to the influence of hydrodynamic pressure, there is a large deviation in the high frequency components of acceleration response, which means the influence of hydrodynamic pressure on the acceleration is closely related to the high frequency components of the earthquake.

The above analysis shows that the deep-water has a great influence on the seismic response of the wind turbine tower, and the curvature at the wind turbine tower bottom is the important reference index for seismic design. Therefore, by using the our proposed simplified calculation method of hydrodynamic pressure, the hydrodynamic pressure is directly converted into the form of additional mass and applied to solving the dynamic motion equation of the wind turbine tower in deep water. We studied the influence of the hydrodynamic pressure on the relationship between bending moment and curvature at the bottom of the wind turbine tower, as shown in Fig.9.

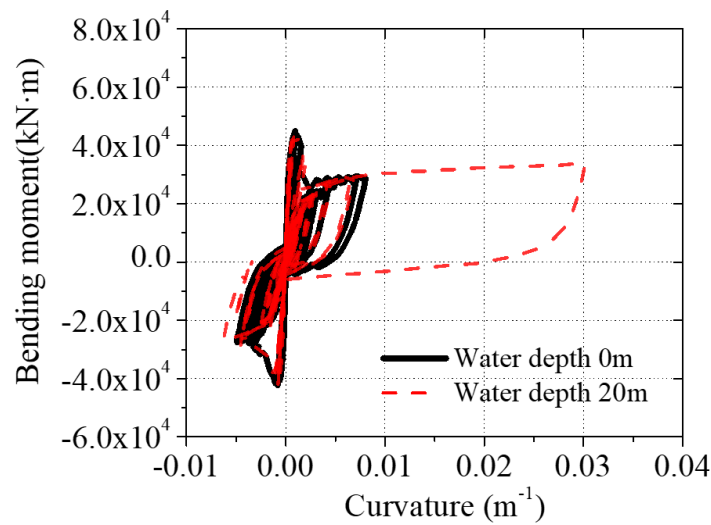

(a) T1-II -1

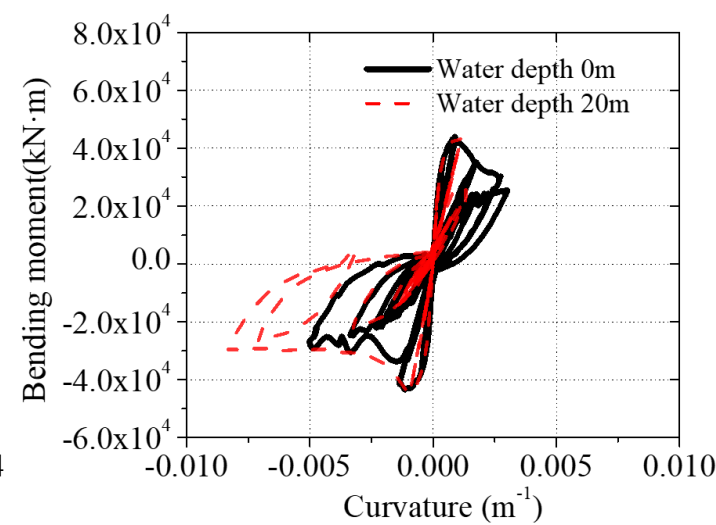

(b) T2-II-1

Fig.9 The relationship between bending moment and curvature under different earthquakes action

As shown in Fig.9, the influence of the water on the bending moment-curvature of the tower bottom is greater than that without the hydrodynamic pressure influence. The bending moment-curvature hysteretic curve shows an inverted $S$ shape more obvious than that without the hydrodynamic pressure influence, which shows that the deformation and energy dissipation capacity of the wind turbine tower are decreased. Therefore, the wall thickness or stiffening rib should be increased to improve the seismic performance and ductility of the wind turbine tower. 


\section{Dynamic response of wind turbine tower in different water depths}

In previous analysis, we found the effect of hydrodynamic pressure on the internal force of wind turbine tower is significant, so the effect cannot be ignored. Next, we investigated the dynamic response of wind turbine tower in different water depths which are $0 \mathrm{~m}, 5 \mathrm{~m}, 10 \mathrm{~m}, 15 \mathrm{~m}$, and $20 \mathrm{~m}$. Because the internal force at the wind turbine tower bottom is the important reference index for seismic design, the influence of the hydrodynamic pressure on internal force at the wind turbine tower bottom in different water depths is calculated, as shown in Fig.10.

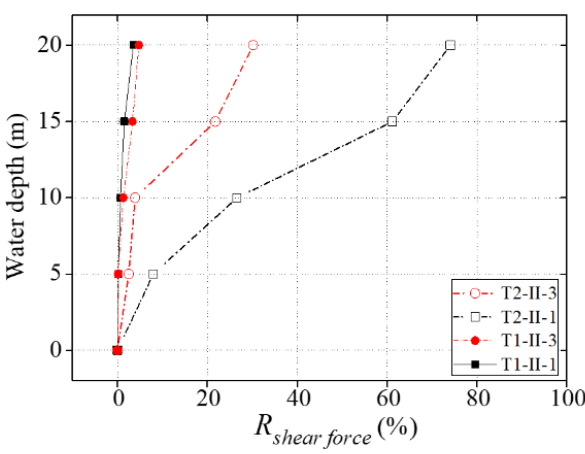

(a) Shear force

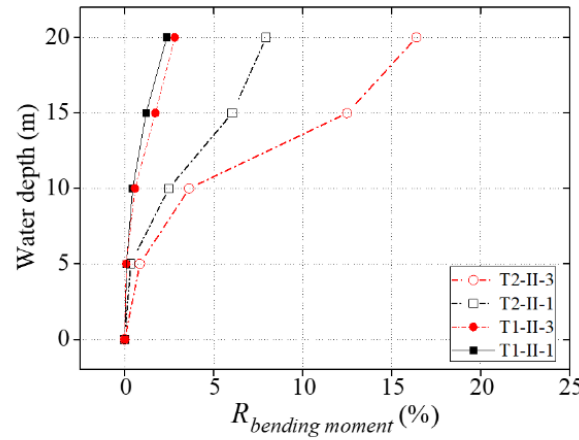

(b) Bending moment

Fig.10 Shear force and bending moment of the wind turbine tower top

Fig.10 shows that the internal force significantly increased with the water depths increasing, which shows that the hydrodynamic pressure in different water depths has a big impact on the internal force at the wind turbine tower bottom. The internal force increases with the increasing of the water depths under different earthquakes. The maximum increase of the shear force is $79.12 \%$, and the maximum increase of the bending moment is $16.93 \%$. In addition, the internal force under near-field earthquakes action is greater than that under far-field earthquakes action. For example, the shear force under earthquake T2-II-1 action increases by $72.4 \%$ than that under earthquake T1-II-1 action, and the bending moment increased by $13.56 \%$ than that under earthquake T1-II-1 action.

The influence of the hydrodynamic pressure on the displacement and acceleration at the wind turbine tower top in different water depths is calculated, as shown in Fig.11.

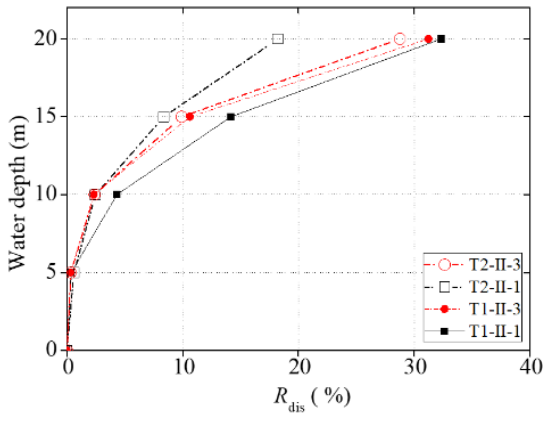

(a) Displacement

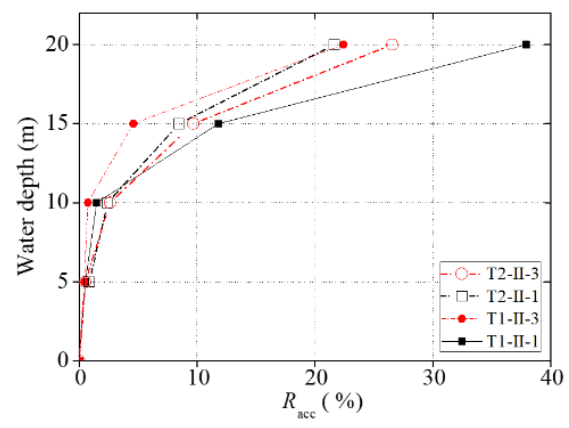

(b) Acceleration

Fig.11 Displacement and acceleration of the wind turbine tower top

As shown in Fig,11, the influence of hydrodynamic force on the displacement and acceleration increases with the increasing of the water depths under different earthquakes. The displacement under far-field earthquakes action is greater than that under near-field earthquake. When the water depth is $5 \mathrm{~m}$, the effect of hydrodynamic force on the displacement is close, which makes the displacement increase about $2.05 \%$. When the water depth is $10 \mathrm{~m}$, the hydrodynamic force makes the displacement increase about $4.65 \%$ under earthquake T1-II-1 action, which is greater than other earthquakes action. When the water depth reaches $20 \mathrm{~m}$, the hydrodynamic force makes the displacement increase by $33.52 \%$ under earthquake T1-II-1 action, which is $14.22 \%$ greater than that under earthquake T2-II-1 action. The effect of hydrodynamic force on the acceleration shows the same rule with the displacement, and the hydrodynamic force makes the acceleration increase by $38.32 \%$ under earthquake T1-II-1 action, and it is $17.25 \%$ greater than that under earthquake T2-II-1 action. 


\section{Validation of simplified calculation model by comparison to shaking-table test data}

To verify the accuracy of the simplified calculation model of water-wind turbine tower affected by earthquake based on added mass method, the shaking-table test of the wind turbine tower is investigated.

\subsection{Test equipment}

The experiment was conducted on a shaking table simulation test system (ES-15) including: a shaking-table controller, shaking table, and hydraulic pump. The main technical parameters of the shaking-table test equipment include its rated working frequency $(100 \mathrm{~Hz})$, maximum acceleration $(20 \mathrm{~m} / \mathrm{s} 2)$, maximum test mass $(5000 \mathrm{~kg})$, and dimensions of the shaking table $(1.5 \mathrm{~m} \times 1.5 \mathrm{~m})$, as shown in Fig. 12 .

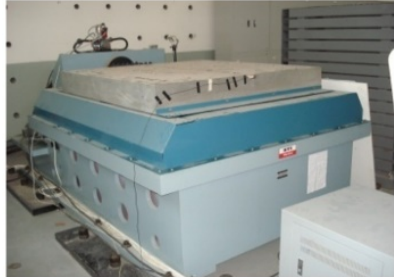

(a) Shaking table

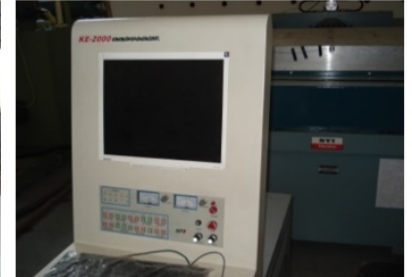

(b) Controller of shaking table

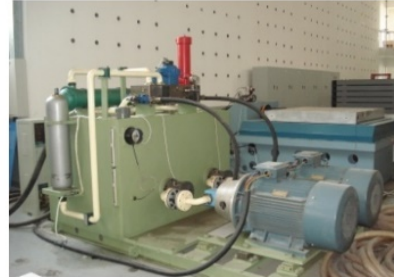

(c) Hydraulic oil pump

Fig.12 Shaking table simulation test system (ES-15)

\subsection{Test model}

This experiment mainly simulates the seismic dynamic interaction between the water and structure to verify the accuracy of the simplified calculation model of water- wind turbine tower as affected by an earthquake based on the added mass method, a large water tank is made to fix on the shaking table and used to hold water. The dimensions of the water tank are $2.0 \mathrm{~m}$ (length) $\times 1.3 \mathrm{~m}$ (width) $\times 1.5 \mathrm{~m}$ (height). The height of the prototype structure is $80 \mathrm{~m}$, and the mass of the upper structure is $265,585 \mathrm{~kg}$. Subject to the size of the test equipment, test water boundary conditions are limited, and the similarity coefficient is $\lambda_{l}=1: 50$ the better to simulate the infinite boundary conditions applicable to the water. The model height is $1.6 \mathrm{~m}$, and the base of the model is welded to steel plate of the tank, as shown in Fig.13.
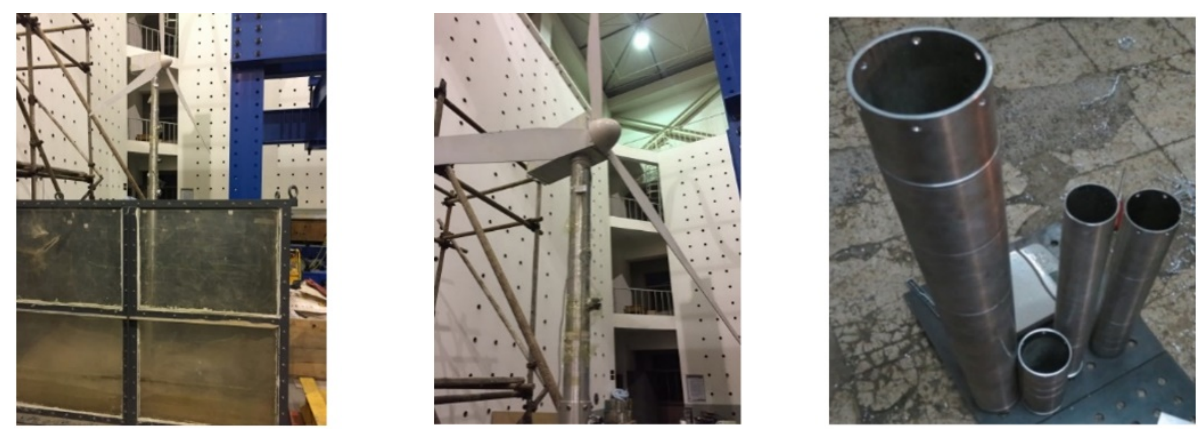

Fig.13 Test model

In the shaking table test, the key is to determine the similarity between the model structure and the prototype structure. The similar design of the model structure follows the following basic principles:

(1) Water, and structure follow the same similar relationship.

(2) Try to ensure that the self-weight of the structure is not distorted, and the mass of the upper structure is also added to the model top in the form of mass blocks given that it does not affect the stiffness of the structure.

(3) The applied dynamic load parameters are controlled to meet the performance requirements of the loading equipment.

According to the design principle of the similarity ratio, non-prototype materials were used in the test, and the elastic force-gravity similarity law was followed. The scaling law between our test model and the actual projects follows the Buckingham-theorem (Xu et al. 2019). The experimental design model is in the elastic response stage, so the model 
material should be consistent with the basic assumption of general elastic theory as far as possible, therefore, similar models can be designed with steel materials. The similarity relations of the main physical quantities of the test model are derived by dimensional analysis method (Table 4).

Table 4 Similarity coefficient of test model

\begin{tabular}{|c|c|c|}
\hline Item & Physical quantity & Similarity coefficient \\
\hline \multirow[t]{3}{*}{ Geometric relationship } & Length & $\lambda_{l}=0.02$ \\
\hline & Displacement & $\lambda_{u}=\lambda_{l}=0.02$ \\
\hline & Area & $\lambda^{2}=4 \times 10-4$ \\
\hline \multirow[t]{5}{*}{ Material relationship } & Elasticity modulus & $\lambda_{E}=6.2$ \\
\hline & Poisson's ratio & $\mu=1.5$ \\
\hline & Stress & $\lambda_{\sigma}=\lambda_{E}=6.2$ \\
\hline & Strain & $\lambda_{\varepsilon}=\lambda_{\sigma} / \lambda_{E}=1$ \\
\hline & Density & $\lambda_{\rho}=3.12$ \\
\hline \multirow[t]{4}{*}{ Dynamic relationship } & Time & $\lambda_{t}=\lambda_{l} \sqrt{\lambda_{\rho} / \lambda_{E}}=0.0142$ \\
\hline & Frequency & $\lambda_{f}=1 / \lambda_{t}=23.81$ \\
\hline & Velocity & $\lambda_{V}=\lambda_{l} / \lambda_{t}=1.41$ \\
\hline & Acceleration & 1 \\
\hline \multirow[t]{3}{*}{ Load relationship } & Point load & $\lambda_{M}=\lambda_{E} \lambda_{l}^{2}=2.48 \times 10-3$ \\
\hline & Bending moment & $\lambda_{M}=\lambda_{E} \lambda_{l}^{3}=1.98 \times 10-4$ \\
\hline & Inertia force & $\lambda_{F}=\lambda_{\rho} \lambda_{l}^{3} \lambda_{a}=1.99 \times 10-4$ \\
\hline
\end{tabular}

\subsection{Experimental scheme}

To measure the dynamic response of the model, four acceleration sensors are placed along the model height, and two displacement sensors are placed at the model bottom and model top, as shown in Table 5.

Table 5 Assignment of the sensors

\begin{tabular}{|c|c|c|c|c|}
\hline Name & Model & Number & Description & A---Acceleration sensor \\
\hline Acceleration sensor & LC0701-5M & $\mathrm{A} 1, \mathrm{~A} 2, \mathrm{~A} 3, \mathrm{~A} 4, \mathrm{~A} 5$ & $\begin{array}{c}\text { Record the acceleration of } \\
\text { the model at different } \\
\text { heights }\end{array}$ & 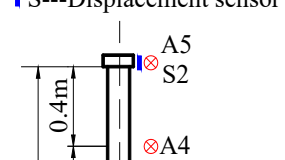 \\
\hline Displacement sensor & SW-1 & S1, S2 & $\begin{array}{l}\text { Record the displacement of } \\
\text { the model bottom and top } \\
\text { (Range } \pm 100 \mathrm{~mm} \text { ) }\end{array}$ & 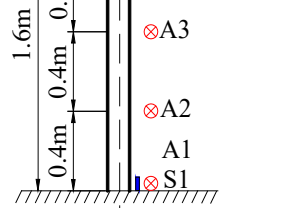 \\
\hline
\end{tabular}


The Tianjin seismic wave and Kobe seismic wave were selected as the input load to simulate these earthquakes. The Tianjin wave is an artificial earthquake, and the Kobe seismic wave is an actual seismic record. The test conditions are listed in Table 6.

Table 6 Test conditions

\begin{tabular}{clc}
\hline Test conditions & Seismic wave type & Peak acceleration (g) \\
\hline Kobe-01 & Kobe earthquake & 0.10 \\
Kobe-02 & Kobe earthquake & 0.20 \\
TJ-01 & Tianjin earthquake & 0.10 \\
TJ-02 & Tianjin earthquake & 0.20 \\
\hline
\end{tabular}

\subsection{Analysis of test results}

In the experiment, the dynamic characteristics of the model with the water influence and without the water influence were measured by hammer decay model test and sine wave sweep test respectively, and the first order vibration frequencies of the model in water depth $0 \mathrm{~m}$ and $0.4 \mathrm{~m}$ are obtained, as shown in Fig.14.

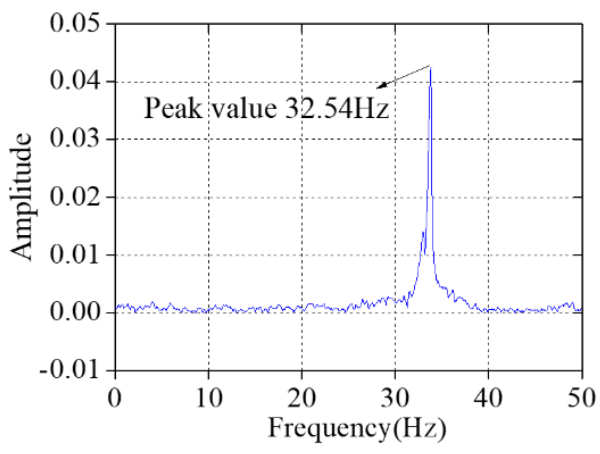

(a) Water depth $0 \mathrm{~m}$

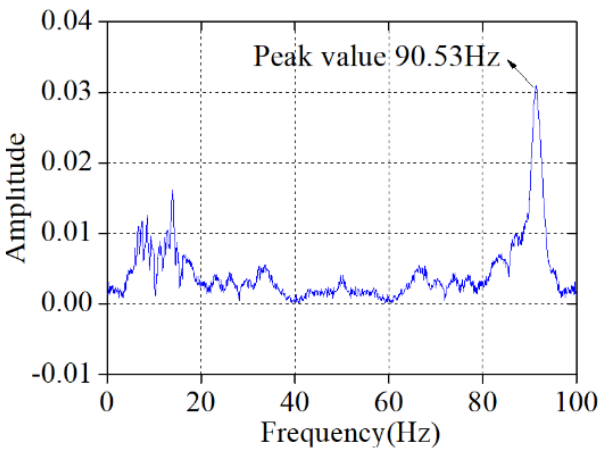

(b) Water depth $0.4 \mathrm{~m}$

Fig.14 Fourier spectrum of the free attenuation

As shown in Fig.14, the natural vibration frequency of the test model with the water influence is obviously higher than that without water influence. The natural vibration frequency of the test model with the water influence is 2.78 times more than that without water influence. This is mainly due to the restraint effect of water which increases the lateral restraint stiffness of the model.

In order to verify the accuracy of our proposed simplified calculation model, we compared the test results and the calculation results using our proposed simplified calculation model when the water depths are $0 \mathrm{~m}$ and $0.4 \mathrm{~m}$. First, we compared the natural frequency, as shown in Table 7.

Table 7 Frequency comparison between the test result and calculation result

\begin{tabular}{|c|c|c|c|c|}
\hline \multirow{2}{*}{ Method } & \multicolumn{2}{|c|}{ Water depth $0 \mathrm{~m}$} & \multicolumn{2}{|c|}{ Water depth $0.4 \mathrm{~m}$} \\
\hline & Frequency $(\mathrm{Hz})$ & Period (s) & Frequency $(\mathrm{Hz})$ & Period (s) \\
\hline Test result & 32.54 & 0.030 & 90.53 & 0.011 \\
\hline Calculation result & 31.12 & 0.032 & 96.87 & 0.010 \\
\hline $\mathrm{R}(\%)$ & -4.36 & 6.67 & 7.00 & -9.09 \\
\hline
\end{tabular}

As shown in Table 7, the error between the test results and calculation results of the frequencies using our proposed simplified calculation model is within $\pm 7 \%$ when the water influence is not considered, and the error is within $\pm 10 \%$ when the water depth is $0.4 \mathrm{~m}$. 
Furthermore, by using the our proposed simplified calculation method of hydrodynamic pressure, the hydrodynamic pressure is directly converted into the form of additional mass and applied to solving the dynamic motion equation of the wind turbine tower in deep water. Based on this, the acceleration and displacement time histories of the model top under Tianjin seismic wave and Kobe seismic wave are calculated when the water depth is $0.4 \mathrm{~m}$, and the comparison results are shown in Fig.15 and Fig.16.

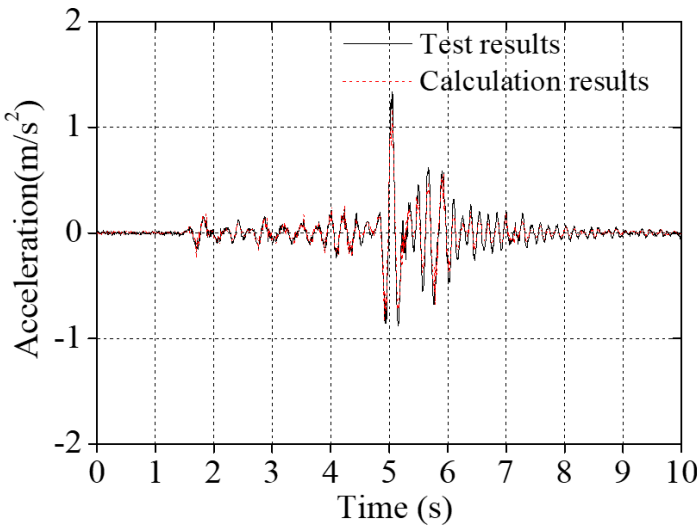

(a) Tianjin earthquake

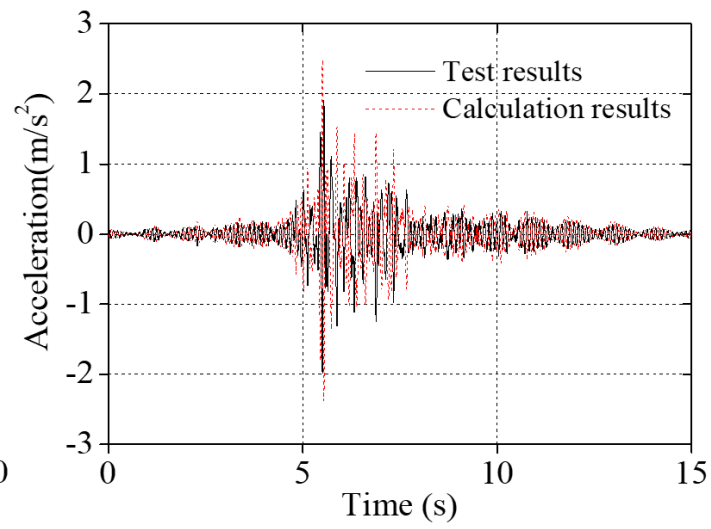

(b) Kobe earthquake

Fig.15 Acceleration of the model top under earthquake (0.1g)

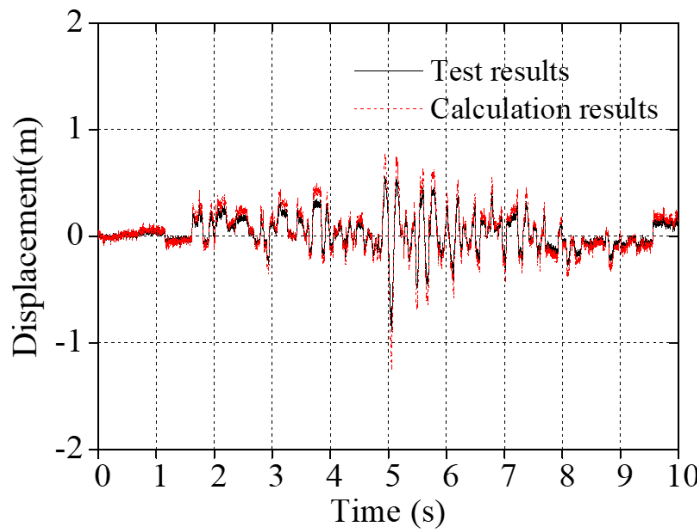

(a) Tianjin earthquake

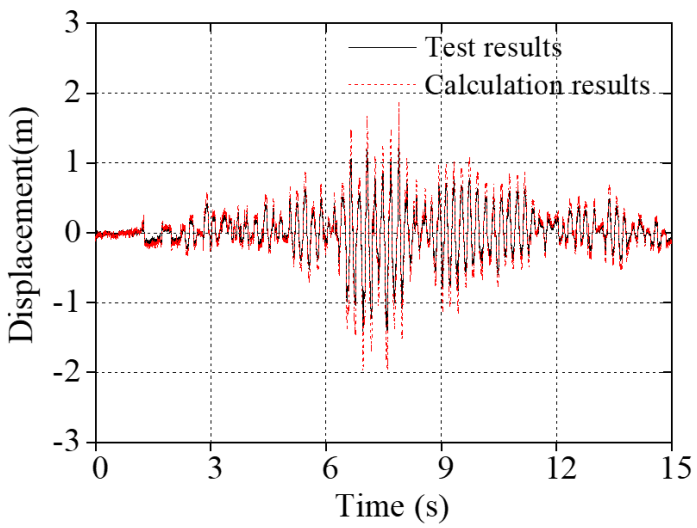

(b) Kobe earthquake

Fig.16 Displacement of the model top under earthquake $(0.1 \mathrm{~g})$

As shown in Fig.15 and Fig.16, the calculated acceleration and displacement at the model top under Tianjin earthquake and Kobe earthquake inputs match the test results; however, the calculated acceleration and displacement are larger than the test results. The reason for this is that the model is the elasto-plastic body, and our proposed calculation model is simplified to some extent. Finally, we compared the calculation results of the peak acceleration and peak displacement along the model height (Figs 17 and 18) 


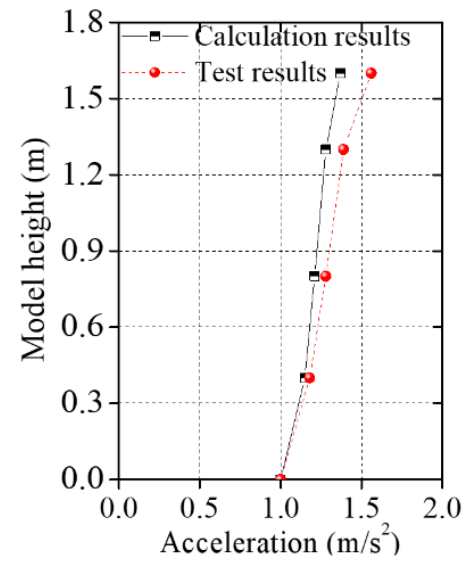

(a) $100 \mathrm{Gal}$

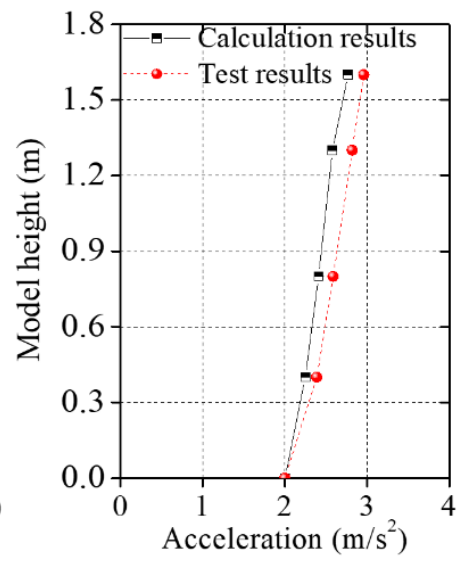

(b) $200 \mathrm{Gal}$

Fig.17 Peak acceleration along the model height under Tianjin earthquake

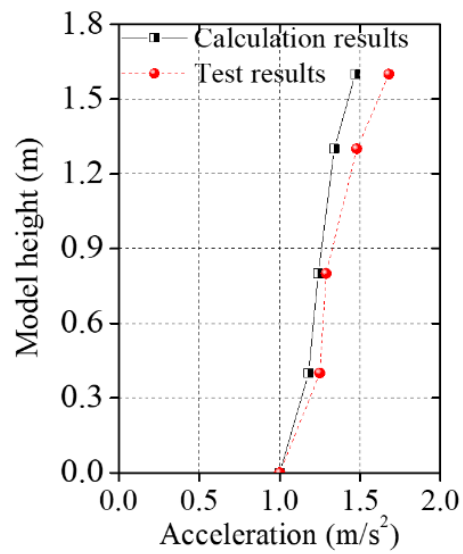

(a) $100 \mathrm{Gal}$

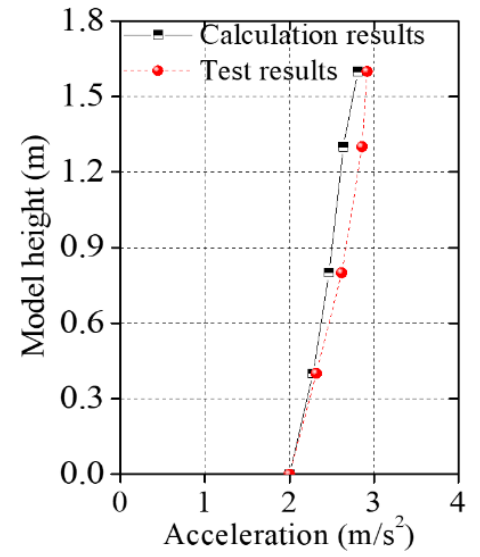

(b) $200 \mathrm{Gal}$

Fig.18 Peak acceleration along the model height under Kobe earthquake

As shown in Fig.17 and Fig.18, the test results of the model under seismic load are consistent with the calculated results, and there is only a certain deviation seen under specific conditions. The maximum difference is $17.36 \%$ under Tianjin earthquake input, and $19.50 \%$ under Kobe earthquake input. In general, the distribution of the peak acceleration calculated by our proposed simplified calculation model along the height of the model is consistent with test data, showing that our proposed simplified calculation model is both accurate and reliable. In addition, we found that all the calculation results are underestimated, and the reason for this is that the added mass calculated by the Morison method is slightly bigger, and the calculated results are more conservation; however, all of the results are within the accepted tolerance for error.

\section{Conclusions}

(1) Based on the Morison hydrodynamic theory, a simplified calculation method of hydrodynamic pressure was proposed, and the approach is suitable for seismic design of the wind turbine tower in the deep-water. Shaking table test of a wind turbine tower model is conducted to evaluate whether the simplified calculation method is accurate or not, and the experimental results is in good agreement with the calculated results using our proposed method, which further demonstrates its effectiveness.

(2) Wind turbine tower in deep water is sensitive to water because it belongs to high-rise structure, and its nature vibration period is long. The hydrodynamic pressure makes the first natural vibration period increase $25.2 \%$, which means the influence of water on the natural vibration characteristics of the wind turbine tower cannot be ignored. The internal force significantly increased with the water depths increasing, and the hydrodynamic pressure of water depth $20 \mathrm{~m}$ makes the shear force increase by $79.12 \%$ while making the bending moment increase by $16.93 \%$. 
(3) The deformation and energy dissipation capacity of the wind turbine tower are decreased affected by hydrodynamic pressure; therefore, the wall thickness or stiffening rib should be increased to improve the seismic performance and ductility of the wind turbine tower. The influence of hydrodynamic pressure on the displacement and acceleration increases with the increasing of the water depths under different earthquakes. The hydrodynamic pressure of water depth $20 \mathrm{~m}$ makes the displacement increase by $33.52 \%$ while making the acceleration increase by $38.32 \%$. In addition, the influence of hydrodynamic pressure on the acceleration and displacement is closely related to the high frequency components of the earthquake.

\section{Acknowledgments}

This work is financially supported by research grants from: The National Natural Science Foundation of China (No. 51708516), Project of China Coal Industry Group Co., Ltd (2019-2-ZD004) and (2019-2-ZD003), The Young Elite Scientists Sponsorship Programme (CAST) (No. 2018QNRC001), and The Hebei Natural Science Foundation (No. E2019210126).

Author's Contributions: S Huang: Conceptualization, Methodology, Software, Investigation, Writing - original draft, Visualization. Q Qi: Methodology, Software, Visualization. W Liu: Writing - review \& editing, Supervision. Y Liu: Conducting Experiments, Formal analysis. Y Zhao:Investigation, Software.

Editor: Marcílio Alves.

\section{References}

Chopra A.K., Goyal A., (1991). Simplified earthquake analysis of intake-outlet towers. Journal of Structural Engineering 117 : 767-788.

Chen Guoxin, Bai Degui, Wang Zhihua, (2008). Seismic response analysis of large scale bridge pier supported by pile foundation considering the effect of wave and current action. Journal of Earthquake Engineering and Engineering Vibration 28:170-177.

Cao Mengqiang, (2013). Hydrodynamic effect on seismic response of elevated pile cap bridge. Lanzhou: Lanzhou Jiaotong University.

Feng Yutao, Rong Jinzhang, Cao Fang, Guo Xiangming, Yu Zhijun, (2006). Seismic response analysis of hydrodynamic and pilesoil-structure interaction for river-spanning bridge. Chinese Journal of Rock Mechanics and Engineering, 25: 2713-2718.

Goto H., Toki K, (1965). Vibration characteristics and aseismic design of submerged bridge piers. Pro.3rd world conference on earthquake engineering New Zealand.

Gao Xuekui, Zhu Xi, (2006). Hydrodynamic effect on seismic response of bridge pier in deep water. Journal of Beijing Jiaotong University 30:55-58.

GB50011-2010 (2010). Code for Seismic Design of Buildings. Beijing: China Architecture and Building Press.

GB50009-2012 (2012). Load code for design of building structures. Beijing: China Architecture and Building Press.

GB50135-2019 (2019). Code for design of high-rising structures. Beijing: China Planning Press.

Hoshikuma J, (2000). Evaluation method of hydrodynamic pressure considering structural ductility seismic. Proceedings of the 4th Bridge Seismic Design Considering Structural Ductility Seismic. Tokyo.

Lai Wei, Wang Junjie, Hu Shide, (2004). Earthquake induced hydrodynamic pressure on bridge pier. Journal of Tongji University 32:1-5.

Lin Zeng, Zhang Yong, Yuan Wancheng, You Kehua, Dang Xinzhi, (2016). Hydrodynamic effect on seismic responses of a multispan cable-stayed bridge in deep water. Structural Engineers 32:77-84.

Morison J.R., O'Brien M.P., Johnson J.W., (1950). The force exerted by surface wave on piles. Petroleum Transactions 19:149158. 
Martinelli L, Barbella G, Feriani A, (2011). A numerical procedure for simulating the multi-support seismic response of submerged floating tunnels anchored by cables. Engineering Structures 33:2850-2860.

Pilato MD, Perotti F, Fogazm P, (2008). 3D dynamic response of submerged floating tunnels under seismic and hydrodynamic exmtation[J]. Engineering Structures 30:268-281.

Japan Road Association, (2002). Specifications for highway bridges·Part V:Seismic Design 1st Ed.Japan: Japan Road Association.

Sun Jingfei, Pan Yisu, (2013). Seismic response comparison of hydrodynamic pressure on bridge pier in deep water. Technology \& Economy in Areas of Communications, 15:39-42.

Terro M J, Rohman M A, (2007). Wave induced forces in offshore structures using linear and nonlinear forms of Morlson's equation. Journal of Vibration and Control 13:139-157.

Westergaard H.M., (1998). Water pressure on dams during earthquakes. Transactions of the American Society of Civil Engineers 1933:418-433.

Walker D A G, Taylor R E, (2005). Wave diffraction from linear arrays of cylinders. Ocean Engineering 32:2053-2078.

Xiang Tao, (2008). Seismic response analysis of a long span continuous rigid frame bridge with high piers in deep resevervior. Chengdu: Southwest Jiaotong University.

Xiang Min, Liu Weihua, (2015). Study of seismic performances of deep sea cable-stayed bridges under hydrodynamic pressure caused by earthquake. Railway Standard Design 59:52-56.

Ye Jian, (2013). Seismic response analysis of bridge in construction of pier water coupling. Harbin: Institute of Engineering Mechanics, China earthquake Administration.

Xu Chengshun, Dou Pengfei, Du Xiuli, Chen Su, Li Xia, (2019). Experimental Study on seismic response of superstructure-pilessoil system design of test plan for large-scale shaking table model experiments. Journal of Disaster Prevention and Mitigation Engineering 39: 365-374.

Zhou Guijie, (2015). Seismic response analysis of long-span deep-water cable-stayed bridge in meizoseismal area[D]. Chengdu: Southwest Jiaotong University.

Zhao Mi, Huang Yiming, Wang Piguang, (2019). Simplified model for the earthquake induced hydrodynamic pressure on rectangular cylinder. Journal of Beijing university of Technology 45:1213-1217.

Zhang Jie, Zhu Dongsheng, Zhang Yongshui, Zeng Jinming, (2012). Seismic response of piers in deep water considering hydrodynamic pressure. Journal of Chongqing Jiaotong University 31:357-361. 